\title{
Hirschsprung's Disease Associated With Ondine's Curse: Report of Three Cases and Review of the Literature
}

\author{
By Essam El-Halaby and Arnold G. Coran \\ Ann Arbor, Michigan
}

\begin{abstract}
- The cases of three full-term infant girls with both Hirschsprung's disease (HD) and Ondine's curse (OC) are presented, and the relevant literature is reviewed. All three patients required endotracheal intubation and assisted ventilation during the first $\mathbf{2 4}$ hours of life because of respiratory distress. The diagnosis of HD was subsequently established at age 13, 16, and 20 days, respectively. The aganglionic segment was confined to the rectum in one case, extended to the splenic flexure of the colon in the second case, and involved the terminal ileum in the third. The definitive treatment (endorectal pull-through) was completed successfully in all three patients, and the postoperative follow-up period was 3 to 34 months. All of them presently have tracheostomies and are maintained on home ventilation. They tolerate being off the ventilator while awake, and have nearly normal bowel habits and growth curves. Two have bilateral ciliary ganglion dysfunction, and one has strabismus. Based on this review, the authors conclude the following. (1) The incidence of the HD associated with $O C$ may be more common than is generally believed $(1.8 \%$ of all their HD patients have $O C$. (2) OC should be suspected in any newborn with HD who requires assisted ventilation in the absence of major cardiopulmonary abnormalities. Likewise, $H D$ should be ruled out in any OC case with gastrointestinal dysfunction. (3) Contrary to the previous impression from the literature, the combination of $O C$ and $H D$ should not be considered fatal, because most such patients can be managed successfully and have a reasonable quality of life. (4) The significant association of HD, OC, and ocular anomalies in all three of the authors' patients further substantiates the syndromic nature of this association, which should alert the clinician to perform regular screening for other possible neurocristopathies such as neuroblastoma.
\end{abstract}

Copyright 11994 by W.B. Saunders Company

INDEX WORDS: Hirschsprung's disease; Ondine's curse; neurocristopathy.

$\mathbf{O}$ NDINE'S CURSE is the failure of automatic respiration during sleep. It is considered a subset of the larger disorder of central alveolar hypoventilation but is not synonymous with idiopathic or primary hypoventilation. ${ }^{1}$ The name Ondine's curse (OC) derives from a German story of a sea nymph (Undine) whose husband jilted her for another female, and he was cursed for his unfaithfulness

From the Section of Pediatric Surgery, C.S. Mott Children's Hospital and the University of Michigan Medical School, Ann Arbor, MI.

Date accepted: April 8, 1993.

Address reprint requests to Amold G. Coran, MD, University of Michigan Pediatric Surgery Associates, L2110 Women's Hospital, Box 0245, Ann Arbor, MI 48109.

Copyright 11994 by W.B. Saunders Company

0022-3468/94/2904-0014\$03.00/0 with loss of automatic breathing, requiring him to remember to breathe continuously. When he finally fell asleep, he died. ${ }^{2,3}$ The eponym "Ondine's curse" was applied for the first time in the medical literature to three patients who were thought to have suffered damage to the medullary carbon dioxide $\left(\mathrm{CO}_{2}\right)$ chemoreceptors as a result of surgery on the high cervical cord and brain stem. ${ }^{3}$ The syndrome was initially described in adults ${ }^{4}$ and later was recognized in infants. ${ }^{5,6}$ It may be acquired as a result of neurological abnormalities ${ }^{7}$ caused by encephalitis, ${ }^{8,9}$ hypoxiaischemia, ${ }^{10}$ or surgical trauma. ${ }^{3,11}$

The diagnosis of $O C$ is considered when there is hypoventilation resulting in progressive hypercarbia and hypoxemia during quiet sleep, which is reversible with assisted ventilation, associated with absent sensitivity to hypercarbia and hypoxia, and if there is absence of any primary cardiothoracic or neuromuscular pathology. ${ }^{6}$ There should be significant differences between blood gas values of the awake state and those obtained during sleep. ${ }^{12}$

Congenital $\mathrm{OC}$ is considered a very rare phenomenon in infancy, with only about 50 reported cases. ${ }^{13}$ Because Hirschsprung's disease (HD) is also relatively uncommon (estimated incidence of $0.02 \%$ ), ${ }^{14,15}$ the association of HD with $\mathrm{OC}$ is extremely rare; this was described for the first time by Haddad et al in $1978,{ }^{16}$ and then by others. ${ }^{13,16-27}$ The prognosis for this association has been considered very poor. ${ }^{20,22}$

Herein we describe three new cases of HD associated with OC and review the relevant literature.

\section{CASE REPORTS}

\section{Case 1}

J.K., a 3,200-g full-term white girl was the product of an uncomplicated pregnancy and normal spontaneous vaginal delivcry. Apgar scorcs were 4 and 8 at 1 minute and 5 minutes, respectively. The patient required endotracheal intubation and intermittent mechanical ventilation for recurrent episodes of apnea and bradycardia shortly after birth. The general physical examination showed no dysmorphic features. An eye examination showed strabismus. There were no obvious cardiopulmonary abnormalities. Seizures developed during the first few days, and mild hypotonia was noted. Results of a computed tomography (CT) scan of the brain, electrocardiogram, electromyograph, and brain stem auditory evoked response (BAER) test were normal. The diagnosis of $O C$ was suspected because of unsuccessful weaning from the ventilator on repeated trials despite low ventilation settings and absence of cardiopulmonary anomalies. Polygraphic monitoring of the patient showed normal oxygen saturation when the patient was 
maintained on continuous positive airway pressure (CPAP) while awake, but apnea hypercarbia and low oxygen saturation during sleep. The patient passed meconium spontaneously within the first 24 hours of life, but had one episode of bilious vomiting during the same period, followed by moderate abdominal distension. On the second day of life, a barium enema was interpretated as normal Because of persistent abdominal distension, rectal suction biopsy was performed. This was diagnostic of HD. Laparotomy was performed 16 days of age, and frozen section biopsies confirmed the diagnosis of $\mathrm{HD}$, with extension of the aganglionosis to $22 \mathrm{~cm}$ proximal to the ileocecal valve. Ileostomy was done in the ganglionated bowel. Tracheostomy was performed subsequently, when the need for long-term ventilation became obvious. The patient was maintained on parenteral nutrition for several weeks postoperatively, with gradual introduction of enteral feeding. She was discharged 25 weeks postoperatively and was maintained on home ventilation. At age 31 months, total colectomy and endorectal pull-through (ERPT) of the ileum were performed successfully. At present, the patient is 57 months old, she las five to seven formed bowel movements per day, is toilet trained, and has passed the normal developmental milestones. She tolerates being off the ventilator while awake, but still requires ventilatory support while sleeping.

\section{Case 2}

R.K., a 2,930-g full-term white girl was born to a 23 -year-old primigravida who had an uncomplicated pregnancy and normal vaginal delivery at another hospital. The Apgar scores were 8 and 8 at 1 and 5 minutes, respectively. Shortly after birth, cyanosis developed, with occasional episodes of apnea. Two repeated doses of narcan were given; transient improvement was noted after the first dose but not after the second. At age 11 hours, mechanical ventilation was required because of the increased frequency of apneic episodes and bradycardia. The patient had no dysmorphic features, and her lungs and heart were normal on the physical examination. Mild hypotonia and unequal nonreactive pupils were noted. Results of a CT scan, ultrasound, and magnetic resonance imaging (MRI) of the brain, and a BAER test were normal. Repeated attempts at weaning the infant from the ventilator were unsuccessful. The patient passed meconium on the second day of life, but abdominal distension was observed. There was delayed evacuation of a gastrografin enema, which did not show a transitional zone. On day 16 of life, the patient was transferred to the C.S. Mott Children's Hospital, where clinical bedside sleep studies showed no respiratory drive and a rapidly increasing $\mathrm{PaCO}_{2}$ and decreasing $\mathrm{PaO}_{2}$. However, the patient tolerated CPAP very well while awake. A suction rectal biopsy performed on the same day showed HD. During laparotomy the next day, aganglionosis extending to the junction of the rectum and sigmoid colon was found, and a primary ERPT without colostomy was performed. A tracheostomy was also done at the same time. The patient did very well postoperatively except for one mild attack of enterocolitis 2 weeks after surgery, which was managed conservatively. At age 3.5 months, she required laparotomy and lysis of adhesion because of a bowel obstruction. Except for mild hypotonia, her developmental progress has been excellent. Her bowel pattern appears normal, with two to three bowel movements per day. She tolerates being off the respirator while awake. Results of urinary catecholamine tests. metajodobenzylguanidine (MIBG) scans, and abdominal ultrasounds remain normal.

\section{Case 3}

L.A.. a 3,510-g full-term white girl was born to a 25 -year-old primigravida whose pregnancy was uncomplicated. A cesarean section (CS) was required because of fetal distress. Apgar scores were 5 and 8 at 1 and 5 minutes, respectively. Intubation and assisted ventilation were required 4 hours after birth because of frequent apneic episodes. During examination, no dysmorphic features were noted, and the chest was normal to auscultation. Cardiac evaluation showed an atrial septal defect. The pupils were unequal, with minimal reaction to light. Results of MRI of the brain and a BAER test were normal, but an electroencephalogram showed generalized dysrhythmia, grade 1 . The diagnosis of $O C$ was made on the basis of polygraphic monitoring of the patient, both while awake and during sleep. The infant passed small amounts of meconium during the first 24 hours of life. At 6 days of age, the abdomen became markedly distended. A barium enema showed a transition zone at the splenic flexure of the colon, and the diagnosis of HD was confirmed by suction rectal biopsy. Both colostomy and tracheostomy were performed at another hospital. At 7 months of age, the child was referred to the C.S. Mott Children's Hospital for definitive care. The colostomy was taken down, and an ERPT was performed along with a descending colectomy. Presently, the patient has seven to 10 formed bowel movements per day, and tolerates being off the ventilator for variable periods while awake, but not while asleep. She has a normal growth curve and uses home ventilation (IP-10 ventilator).

\section{LITERATURE REVIEW}

Twenty six cases of congenital OC associated with HD (including our three patients) have been reported (Table 1). The gender distribution for 24 patients was equal (in two cases, sex was not reported). Of the 11 children for whom race was reported, eight were white and three were black. The pregnancy was uneventful in 17 , associated with polyhydramnios in three, and not described in six cases. The method of delivery was vaginal in 15 cases, $\mathrm{CS}$ in five, and not described in six. Gestational age was reported in 23 cases; 20 infants were full-term, and three were premature. Birth weight for gestational age was normal for 14 of 17 infants. Good Apgar scores were reported for 11 of 15 infants, but deterioration of respiratory status necessitated endotracheal intubation and mechanical ventilation (from a few minutes to a few hours after birth) in 18 of 21 infants. Delayed intubation and assisted ventilation were reported in three cases (day 2 , day 4 , month 3 ).

The diagnosis of HD was established within the first week of life for 12 infants, and within the first 2 to 3 weeks of life for seven patients. (In seven cases, the age at diagnosis of $\mathrm{HD}$ was not reported.) The involvement of the aganglionic segment was as follows: in six, rectum or rectosigmoid (four girls, two boys); in two, descending colon (both girls); in 12, total colon aganglionosis with or without distal ileum involvement (six boys, four girls; sex was not reported for the other two); in four, mid or proximal jejunum (two boys, two girls); and in two, unknown. Definitive surgery (pull-through) was performed in eight patients. Both HD and OC occurred in two siblings and two half-siblings. In two cases, there was a family 


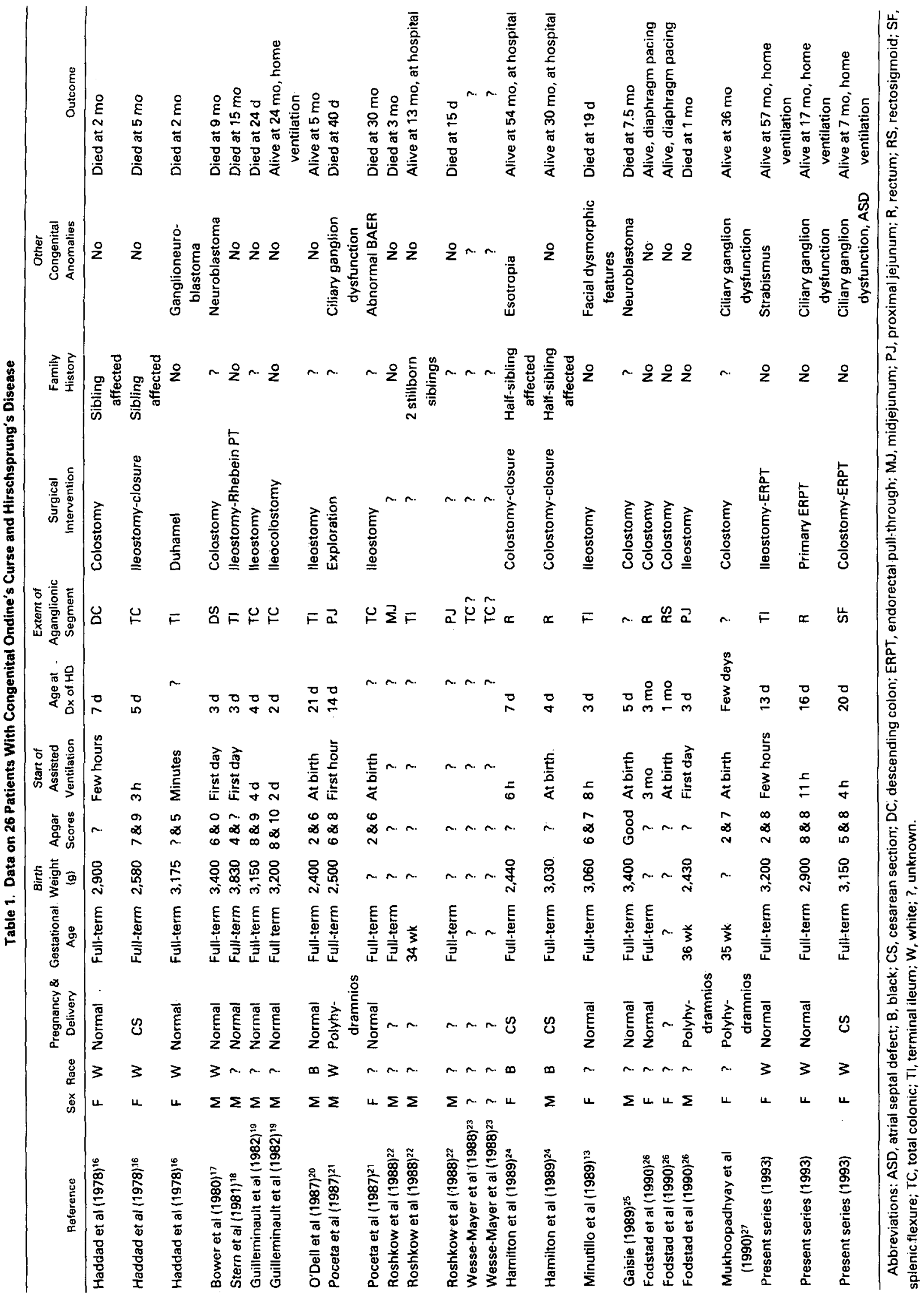


history of a previous still birth in which the cause was unknown. The most common associated anomalies were ocular (5), neuroblastoma or ganglioneuroblastoma (3), cardiac (2), deafness (1), facial dysmorphic features (1), and cerebral arteriovenous malformation (1). Thirteen patients died, and 11 are alive. No specific brain stem focal pathology was noted in 10 cases for which autopsies were performed.

\section{DISCUSSION}

Automatic respiration is stimulated by a rhythmic discharge of the respiratory center neurons in the medulla (dorsomedially in the nucleus tractus solitarus, and ventrolaterally near the nucleus retroambigous), and regulated by chemical stimuli through both central and peripheral chemoreceptors as well as nonchemical stimuli such as pulmonary baroreceptors. ${ }^{1}$ Central chemoreceptors respond to cerebrospinal fluid hydrogen ion changes, determined predominantly by changes in $\mathrm{PaCO}_{2},{ }^{28}$ whereas peripheral receptors respond mainly to $\mathrm{PaO}_{2}$ and $\mathrm{pH}$ changes. ${ }^{29}$ $\mathrm{A} \mathrm{CO}_{2}$ ventilatory response is not necessary in the infant at rest, except during quiet sleep. ${ }^{30}$ Awake ventilation is maintained either by a hypoxemic stimulus or by conscious control. ${ }^{31}$ Neural output from nonchemoreceptor sources may be sufficient to drive ventilation while awake and during rapid eye movement (REM) sleep, but is absent or becomes inhibited in the quiet sleep state. ${ }^{30}$ Malfunction of the central chemoreceptors results in loss of automatic respiration during quiet sleep, and this represents the syndrome of OC. ${ }^{24}$

In 10 cases with known autopsy findings, neither specific CNS pathology nor focal lesions in the brain stem were found. Although hypothalamic focal disease, ${ }^{32}$ absence of the external arcuate nucleus, ${ }^{33}$ and decreased density of neurons and myelinated nerve fibers in the respiratory center ${ }^{34}$ have been found in single cases, it is generally accepted that congenital OC is not associated with major CNS abnormalities. ${ }^{35}$ Liu et $\mathrm{al}^{36}$ suggested the presence of such abnormalities at the molecular level. CT scans, MRI, and cranial ultrasound examinations of the brain have not shown specific brain stem pathology. Wesse-Mayer et $\mathrm{al}^{23}$ postulated that the lesions may be beyond the resolution of current imaging modalities. Abnormal BAER findings were reported in two of the five cases with known results. Similar findings have been reported previously. ${ }^{37,38}$

Our three cases have been seen within the last 5 years and represent $1.8 \%$ of all HD cases treated since 1974 (170 patients) at our institution. The incidence of $\mathrm{HD}$ is $43 \%$ (three of seven) among all cases of congenital OC on home ventilation, managed at our hospital. These 26 cases represent a $50 \%$ incidence of $\mathrm{HD}$ among all published congenital OC cases. These data clearly establish the association of $\mathrm{OC}$ and $\mathrm{HD}$, which may be caused by a primary defect of the stem serotonergic nerve cells, both in the brain stem and the alimentary tract, ${ }^{16}$ or may result from a neural crest migrational abnormality. ${ }^{17}$

Congenital OC has been reported in association with congenital neuroblastoma ${ }^{16,39}$ and ganglioneuroblastoma. ${ }^{40}$ Boland ${ }^{41}$ applied the term "neurocristo pathy" to lesions resulting from maldevelopment of the neural crest tissues, such as pheochromocytoma, medullary carcinoma of the thyroid, carcinoid tumors, and HD. Neuroblastoma and ganglioneuroblastoma were diagnosed at birth in three patients $(11.5 \%)$. Ciliary ganglion dysfunction and abnormal ocular movements were present in five children (19\%) and congenital deafness in one (4\%). ${ }^{42}$ These associated anomalies support the concept of a common embryologic neural crest abnormality. ${ }^{39}$

The gender distribution was equal, which can be explained by the high percentage of long-segment and total colonic aganglionosis with or without proximal small intestinal extension. The white:black ratio was 2.6:1 among 11 patients. An uneventful pregnancy was noted in $85 \%$, and a normal vaginal delivery was described in $75 \%$ of cases with a known pregnancy/ delivery history. Most of the infants $(87 \%)$ were full-term, with a birth weight appropriate for gestational age. Good Apgar scores were reported in 69\% of the cases, but endotracheal intubation and assisted ventilation were required within the first 24 hours after birth in almost all newborns. There was no significant delay in the diagnosis of HD in most patients. The aganglionic segment was classic (rectum or rectosigmoid) in only $25 \%$ of these cases, in contrast to the gencral population of paticnts with HD (66.3\% to $77.7 \%) .{ }^{43,44}$ Obviously, the association between $\mathrm{OC}$ and $\mathrm{HD}$ increases as the proximal extension of aganglionosis increases. Two siblings and two half-siblings (15.4\%) were among the 26 patients. Haddad et al ${ }^{16}$ suggested an autosomal recessive inheritance of $\mathrm{HD}$-associated $\mathrm{OC}$; however, Badner et $\mathrm{al}^{15}$ found a dominant gene inheritance in long-segment $\mathrm{HD}$. A recessive gene with very low penetrance appears to be the most likely pattern of inheritance for standard HD. ${ }^{15}$

Many drugs have been used in therapeutic trials for the management of OC, with limited or no success. . $^{45,46}$ Long-term assisted mechanical ventilation ${ }^{47}$ or diaphragmatic pacing are the current preferred methods of treatment for OC. Diaphragmatic pacing was reported in two cases in this study, and resulted in successful weaning from mechanical ventilation. ${ }^{26}$ In 
several other reported cases of $O C$ without $H D$, results were similar. ${ }^{5,40,48}$ Diaphragmatic pacing appears to be effective in reducing pulmonary vascular resistance and pulmonary hypertension, ${ }^{49}$ but its long-term use can lead to loss of phrenic nerve conductivity. ${ }^{50}$

The outcome of $\mathrm{HD}$-associated $\mathrm{OC}$ was very poor in the earlier cases in this collective review. Death usually resulted from repeated bouts of pulmonary infection or heart failure secondary to pulmonary hypertension caused by hypoxemia. ${ }^{6}$

Our three cases had some unique characteristics. They represent the spectrum of HD (standard, long- segment involving the descending colon, and total colonic aganglionosis with distal ileal involvement). Ocular abnormalities were observed in all. The ERPT procedure was successful in all three children, with nearly normal bowel habits noted during at follow-up. Presently these patients are being managed successfully with home ventilation, and they have reached normal developmental milestones.

This review of our three cases and those in the literature clearly indicates that a high index of suspicion will result in the diagnosis of more cases of ncurocristopathies, with various combinations.

\section{REFERENCES}

1. Tamarin FM, Goldberg RJ, Brandstetter RD: The tale of Ondine: A curse, a kiss, a clasp, and a comment. N Y State J Med 89:196-198, 1989

2. Giraudoux J: Ondine, A Romantic Fantasy in Three Acts. English version by M. Valency. New York, NY, Samuel French, 1956

3. Severinghaus JW, Mitchel RA: Ondine's curse. Failure of respiratory center automatically while awake. Clin Res 10:122, 1962

4. Ratto O, Briscoe WA, Morton JW, et al: Anoxaemia secondary to polycythemia and polycythemia secondary to anoxemia. Am J Med 19:958-965, 1955

5. Mellins RB, Balfour HH JR, Turino GM, et al: Failure of automatic control of ventilation (Ondine's curse). Report of an infant born with this syndrome and review of the literature. Medicine (Baltimore) 49:487-504, 1970

6. Deonna T, Arczynska W, Torrado A: Congenital failure of automatic ventilation (Ondine's curse). A case report. J Pediatr 84:710-714, 1974

7. Stankiewicz JA, Pazevic JP: Acquired Ondine's curse. Otolaryngol Head Neck Surg 101:611-613, 1989

8. Jensen TH, Hansen PB, Brodersen P: Ondine's curse in listeria monocytogenes brain stem encephalitis. Acta Neurol Scand 77:505-633, 1988

9. Giangaspero F, Schiavina M, Sturani $C$, et al: Failure of automatic control of ventilation (Ondine's curse) associated with viral encephalitis of the brainstem: Clinicopathologic study of one case. Clin Neuropathol 7:234-237, 1988

10. Beal MF, Richardson EP Jr, Brandstetter R, et al: Localized brainstem ischemic damage and Ondine's curse after near drowning. Neurology 33:717-21, 1983

11. Fielding JW, Tuul A, Hawkins RJ: "Ondine's curse." A complication of upper cervical-spine surgery. J Bone Joint Surg [Am] 57:1000-1001, 1975

12. Mather SJ: Ondine's curse and the anaesthetist. Anaesthesia 42:394-403, 1987

13. Minutillo C, Pemberton PJ, Goldblatt J: Hirschsprung's disease and Ondine's curse: Further evidence for distinct syndrome. Clin Genet 36:200-203, 1989

14. Passarge E: The genetics of Hirschsprung's disease. Evidence for heterogenous etiology and a study of sixty three families. N Engl J Med 276:138-143, 1967

15. Badner JA, Sieber WK, Garver KL, et al: A genetic study of Hirschsprung's disease. Am J Hum Genet 46:568-580, 1990

16. Haddad GG, Mazza NM, Defendini $R$, et al: Congenital failure of automatic control of ventilation, gastrointestinal motility and heart rate. Medicine (Baltimore) 57:517-526, 1978
17. Bower RJ, Adkins JC: Ondine's curse and neurocristopathy Clin Pediatr 19:665-668, 1980

18. Stern M, Hellwege HH, Gravinghoff L, et al: Total aganglionosis of the colon (Hirschsprung's disease) and congenital failure of automatic control of ventilation (Ondine's curse). Acta Paediatr Scand 70:121-124, 1981

19. Guilleminault C, McQuitty I, Ariagno RL, et al: Congenital central alveolar hypoventilation syndrome in six infants. Pediatrics 70:684-694, 1982

20. O'Dell K, Staren E, Bassuk A: Total colonic aganglionosis (Zuelzer-Wilson syndrome) and congenital failure of automatic control of ventilation (Ondine's curse). I Pediatr Surg 22:1019. 1120,1987

21. Poceta JS, Strandjord TP, Badura RJ Jr, et al: Ondine's curse and neurocristopathy. Pediatr Neurol 3:370-372, 1987

22. Roshkow JE, Haller JO, Berdon WE, et al: Hirschsprung's disease, Ondine's curse, and neuroblastoma manifestations of neurocristopathy. Pediatr Radiol 19:45-49, 1988

23. Wesse-Mayer DE, Brouillette RT, Naidich TP, et al: Magnetic resonance imaging and computerized tomography in central hypoventilation. Am Rev Respir Dis 173:393-398, 1988

24. Hamilton J, Bodurtha JN: Congenital central hypoventilation syndrome and Hirschsprung's disease in half sibs. $J$ Med Genet 26:272-274, 1989

25. Gaisie G: Hirschsprungs disease, Ondine's curse, and neuroblastoma-Manifestations of neurocristopathy. Pediatr Radiol 20 136,1989 (letter)

26. Fodstad H, Ljunggren B, Shawis R: Ondine's curse with Hirschsprung's disease. Br J Neurosurg 4:87-93, 1990

27. Mukhoopadhyay S, Wilkinson PW: Cerebral arteriovenous malformation, Ondine's curse and Hirschsprung's disease. Dev Med Child Neurol 32:1087-1089, 1990

28. Pappenheimer JR, Fend V, Heisy SR, et al: Role of cerebral fluids in control of respiration as studied in unanaesthetized goat. Am J Physiol 203:436, 1965

29. Rebuck AS, Woodley WE: Ventilatory effects of hypoxia and their dependence on $\mathrm{PCO}_{2}$. J Appl Physiol 38:16, 1975

30. Shannon OC, Marsland DW, Gould JB, et al: Central hypoventilation during quiet sleep in two infants. Pediatrics 57:342 346,1976

31. Strieder DJ, Baker WG, Baringer JR, et al: Automatic respiratory failure. Arch Neurol 29:46, 1973

32. de Ri vage SK, Winter RJ, Brouillette $R T$, et al: Idiopathic hypothalamic dysfunction and impaired control of breathing. Pediatrics 75:896-898, 1985

33. Folgering $\mathrm{H}$, Kuyper F, Kille JF: Primary alveolar hypoventilation (Ondine's curse syndrome) in an infant without external 
arcuate nucleus. Case report. Bull Eur Physiopathol Respir 15:659665,1979

34. Kafer ER, Leigh J: Recurrent respiratory failure associated with the absence of ventilatory response to hypercapnia and hypoxaemia. Am Rev Respir Dis 106:100-108, 1972

35. Brazy LE, Kinney HC, Oakes WJ: Central nervous system structural lesions causing apnea at birth. J Pediatr 111:163-175. 1987

36. Liu HM, Loew JM, Hunt CE: Congenital central hypoventilation syndrome: A pathologic study of neuromuscular system. Neurology 28:1013-1019, 1978

37. Long KJ, Allen N: Abnormal brain-stem auditory evoked potentials following Ondine's curse. Arch Neurol 41:1109-1110, 1984

38. Beckerman R, Meltzer J, Sola A, et al: Brain-stem auditory response in Ondine's syndrome. Arch Neurol 43:698-701, 1986

39. Gaisie G, Kook SO, Young LW: Coexistent neuroblastoma and Hirschsprung's disease-Another manifestation of the neurocristopathy. Pediatr Radiol 8:161-163, 1979

40. Hunt CE, Matalon SV, Thompson TR: Central hypoventilation syndrom-Experience with bilateral phrenic nerve pacing in 3 neonates. Am Rev Respir Dis 188:23-28, 1978

41. Boland RP: The neurocristopathies: A unifying concept of disease arising in neural crest maldevelopment. Hum Pathol 5:409-429, 1974
42. Dooling EC, Richardson EP Jr: Ophthalmoplegia and Ondine's curse. Arch Ophthalmol 95:1790-1793, 1977

43. Lister J, Tam PK: Hirschsprung's disease, in Lister J, Irving IM (eds): Neonatal Surgery (ed 3). London, England, Butterworths, 1990, pp 523-546 (chap 37)

44. Sieber WK: Hirschsprung's disease, in Welch KJ, Randolph JG, Ravitch MM, et al (eds): Pediatric surgery (ed 4). Chicago, IL, Year Book Medical, 1986, pp 995-1020 (chap 106)

45. Morimoto $T$, Nagao $H$, Matsuda $H$, et al: Ondine's curse: Therapeutic trial of dimeflin. Brain Dev 5:567-571, 1983

46. Naeije N, Melot C, Naeije R, et al: Ondine's curse. Report of a patient treated with almitrine, a new respiratory stimulant. Eur J Respir Dis 63:342-346, 1982

47. Chang YL, Meerstadt PW: Congenital central alveolar hypoventilation syndrome (Ondine's Curse): Effectiveness of early home ventilation for normal development. Postgrad Med J 67:471473,1991

48. Yasuma F, Nomura $H$, Sotobata I, et al: Congenital central alveolar hypoventilation (Ondine's curse): $A$ case report and review of the literature. Eur J Pediatr 146:81-83, 1987

49. Langou RA, Cohen LS, Sheps D, et al: Ondine's curse: Hemodynamic response to diaphragm pacing (electrophrenic respiration). Am Heart J 95:295-300, 1978

50. Zwillich C, Kryger M, Weil J: Hypoventilation: Consequences and management. Adv Intern Med 23:287-309, 1978 